\title{
The Morphophonology of Moroccan Arabic Derived Causatives *
}

\author{
Ayoub Noamane ** \\ (Mohammed V University, Morocco)
}

\begin{abstract}
This paper aims at investigating the morphophonological make-up of derived causatives in Moroccan Arabic within the framework of Optimality Theory (Prince \& Smolensky, 2004). Causative verbs in MA are characterized by the systematic gemination of their medial consonants. However, it is not easy to determine the morphological nature of the causative morpheme involved in this derivation. Also, it is not clearly known why the causative morpheme gets realized exactly on the second segment of the base form. Therefore, we seek to achieve the following goals. First, we intend to determine the nature of the causative morpheme. Second, we aim to explain why the causative morpheme is realized on the second segment of the base form. In this respect, we show that the causative morpheme is represented by a featureless consonantal mora that targets the second segment of the base root, turning it into a geminate. We also show that the causative morpheme gets infixed thanks to the privileged status of root-initial segments.
\end{abstract}

Keywords: causative verbs, morphophonology, germination, word formation, infixation, Optimality Theory, Moroccan Arabic

\section{Introduction}

In Moroccan Arabic (MA), morphological causatives (MCs) are derived via geminating the second segment of the root (e.g. $\sqrt{ } k t b$ 'to write' $>>k a t t a b$ 'to make write'). This process is often described as a case of stem modification, whereby an operation applies to a base form and changes it without adding any segmental material. Morphologists see stem modification as difficult to accommodate in a concatenation-based model (Anderson, 1992). This paper, however, seeks to argue in favor of a morpheme-based approach to deriving MCs in MA. The ultimate goal is to extend the range of concatenative patterns to include instances of stem modification (lengthening is a case in point), hence emphasizing the

\footnotetext{
* I would like to thank Karim Bensoukas, Ayoub Loutfi and Aziz Boudlal for their valuable comments and suggestions. I would also like to thank the audience of the $3^{\text {rd }}$ International Doctoral Conference on Arabic Comparative Linguistics, held at Ibn Tofail University-Kenitra in May 2015, for their feedback on an earlier version of this study. I am solely responsible for any errors.

** Ayoub Noamane: Assistant Professor, Department of English Studies, Faculty of Letters and Human Sciences, Mohammed V University in Rabat, Morocco. E-mail: noamane.ayoub@gmail.com.
} 
claim that concatenation is an inherent property of the morphological system despite the apparent exceptions. In this regard, there are three main questions that this paper tries to answer: (i) What is the nature of the causative morpheme in MA? (ii) Why is the causative morpheme realized on the second segment of the root in exclusion of the other segments? (iii) What is the base form for deriving MCs in MA?

In response to these questions, we are proposing a constraint-based analysis of morphological causatives in MA cast within the framework of Optimality Theory (OT) (Prince \& Smolensky, 2004; McCarthy \& Prince, 1993a, 1995, 1999). We show that OT offers an appropriate analytical device which successfully eschews problems that were encountered elsewhere. In particular, this paper addresses the substantial relevance of three OT offshoots, notably the theories of Generalized Alignment (McCarthy \& Prince, 1993b), Positional Faithfulness (Beckman, 1998) and Morpheme Realization (Kurisu, 2001). In particular, it will be demonstrated that an alignment constraint affixes a consonantal mora at the left edge of the root. The posited affix is misaligned due to some phonological requirement on output well-formedness, namely the privileged status of the initial radical element. The realization of the causative morpheme is then ensured by a constraint dubbed Realize Morpheme (RM). The final result is the occurrence of a medial geminate in the causative structure.

The organization of this paper is mapped out as follows. Section 2 describes the patterns of morphological causatives in MA and summarizes previous accounts. Sections 3 and 4 lay out the ground for our analysis by specifying the various arguments in support of both the affixal and moraic analyses. Section 5 discusses Generalized Alignment as a representative model of affixation in OT. In section 6, we examine the concept of Positional Faithfulness and claim that it plays a key role in the formation of the causative pattern as it appears in MA. Section 7 highlights the role of the Realize Morpheme constraint in ensuring the manifestation of the causative morpheme. Section 8 outlines our proposal to answer how causatives are derived in MA through the interaction of constraints à la Optimality Theory. This is done by ranking the constraints in action. Section 9 introduces the constraints responsible for the syllabification of the derived forms. Section 10 concludes.

\section{Morphological causatives in Moroccan Arabic}

\subsection{Description}

In MA, morphological causatives are characterized by being morphologically marked. These forms are interpreted as verbs with an extended meaning that incorporates the meaning of the base and the meaning of the causative affix. The latter is realized by dint of lengthening the second segment of the base. The examples in (1) are illustrative items of 
morphological causatives in MA:

\begin{tabular}{|c|c|c|}
\hline \multicolumn{2}{|c|}{ Base form } & Causative Form \\
\hline$k t b$ & 'to write' & $k a t t a b$ \\
\hline hrb & 'to run away' & harrab \\
\hline $\int r b$ & 'to drink' & farreb \\
\hline$x_{r}$ & 'to go out' & xarraz \\
\hline$d x l$ & 'to get in' & $d \partial x x a l$ \\
\hline$k m i$ & 'to smoke' & kəmmi \\
\hline$x w i$ & 'to empty' & $x \partial w w i$ \\
\hline$f i q$ & 'to wake up' & $f_{\partial j j} j q q$ \\
\hline$g u l$ & 'to say' & gawwal \\
\hline
\end{tabular}

For example, the causative verb kattab consists of two different morphemes. First, the base morpheme $k t a b$ has the form of a simple verb and indicates the action of writing, "to write". Second, the causative morpheme contributes the meaning of causativity and is encoded in the form of a geminate $-t t$. The geminate of every causative must match the featural specifications of the second segment of its corresponding base form.

In MA, every morphological causative verb falls into one of the following patterns: $\mathrm{C} ə \mathrm{CC} ə \mathrm{C}$ or $\mathrm{C} ə \mathrm{CCV}$ - where $\mathrm{C}$ and $\mathrm{V}$ indicate a consonant and a full vowel ${ }^{\mathbb{1}}$, respectively, as shown in (2):

(2) Causative patterns:

\begin{tabular}{|c|c|c|}
\hline a. $\mathrm{C} 2 \mathrm{CC} 2 \mathrm{C}$ & & $\mathrm{CaCCV}$ \\
\hline ijjạ 'to whiten' & lawwi & 'to twist' \\
\hline rrg̣ad 'to sicken' & qarr?i & 'to teach' \\
\hline$r a b$ 'to speed up' & $d \partial f f i$ & 'to warm \\
\hline 'to waken up' & $n \partial \boldsymbol{q q} i$ & 'to clean' \\
\hline las 'to smooth' & worri & 'to show' \\
\hline
\end{tabular}

The difference between the items in (2a) and those in (2b) stems from the fact that they are derived from distinct base shapes. Pattern (b) includes those causative verbs that are based on final weak tri-literal verbs, where a full vowel appears at the end of the verb. Pattern (a), however, incorporates causative verbs that are derived from all the other types of base forms. Hence, the pattern $\mathrm{C} ə \mathrm{CC} ə \mathrm{C}$ is more productive and subsumes the majority of causative verbs in MA.

\subsection{Previous accounts}

The analysis presented in the current work builds on previous treatments that deal with the same data set. These treatments primarily include the pre-OT circumscription analysis

\footnotetext{
(1) The vocalic inventory of Moroccan Arabic consists of three full (i.e. underlying) vowels: /u/, /i/ and /a/.
} 
of Bennis (1992), the pre-OT autosegmental analysis of Bennis \& Iazzi (1995) and the OT partial reduplication analysis of Boudlal (2001). To begin with, Bennis (1992) holds that the causative in MA is derived from full-fledged word forms (i.e. nouns, verbs and adjectives) via the affixation of a heavy syllable (i.e. bimoraic) to a circumscribed prosodic constituent that can be in the shape $-\mathrm{C} \partial \mathrm{C}$ or $\mathrm{CV}$. To exemplify this, the causative ləSৎəb 'to make play' is taken to be derived from the verb $l \varsigma a b$ by prefixing the heavy syllable (i.e. $\left.\sigma_{\mu \mu}\right)$ to the domain $(-\{\partial b)$. The argument is that one mora generates a geminate while the other mora triggers schwa epenthesis.

(3) The prosodic circumscription analysis

$$
\begin{aligned}
& \text { Aff Caus: } \quad l \varsigma \partial b=\sigma_{\mu \mu^{-}} \varsigma_{\partial} b * l \\
& =-\partial \uparrow \uparrow \partial b * l \\
& =l \partial \varsigma \varphi_{\partial} b
\end{aligned}
$$

There are two aspects for which this analysis can be criticized. First, it rests heavily on the notion of extraprosodicity in that it assumes that a segment remains inert and stays out of the derivational procedure, while the morphological process of affixation targets a well-defined prosodic constituent. This notion is employed to explain the occurring infixation phenomenon in causatives. In our analysis, however, the infixation of the causative morpheme is attained simply via constraint interaction.

Second, the causative affix is believed to be a heavy syllable (i.e. $\sigma_{\mu \mu}$ ) which consists of two moras: one to motivate schwa epenthesis and the other to trigger consonant gemination. Nonetheless, it has been shown elsewhere (Bensoukas \& Boudlal, 2012a-b) that schwa in MA is nonmoraic. Instead, the nucleus schwa and the following coda consonant share a single branching mora. Grounded on this fact, our analysis limits the prosodic shape of the causative morpheme to one mora responsible for consonant lengthening. Schwa, on the other hand, is independently motivated in that it is epenthesised to break up impermissible consonant clusters.

Using the representational premises of autosegmental phonology, Bennis \& Iazzi (1995) provides an alternative account of causative derivation in MA. The central claim of this work is that the causative template has the shape XXXX, where $\mathrm{X}$ refers to an underspecified position in the segmental tier. This template is then associated with a lexical entry as follows. First, the second radical element is pre-associated with the third position in the template. Second, the other segments spread to associate with the remaining corresponding positions in the template. Finally, the rules of syllabification apply. Below is an example of deriving the causative doxxal 'to make enter':

(4) The autosegmental analysis 
The Morphophonology of Moroccan Arabic Derived Causatives

\begin{tabular}{|c|c|c|c|}
\hline Lexical entry & Pre-association & Spreading & Syllabification \\
\hline & X X X X & $\underset{1}{X} \quad \underset{1}{X} \quad X \underset{1}{X}$ & \\
\hline$/ d x l /$ & $d \times l$ & $d x$ & daxxal \\
\hline
\end{tabular}

A major shortcoming of this analysis is that it resorts to an ad-hoc solution to explaining the internal gemination that has come to characterize the causative verb in MA. Neither right-to-left nor left-to-right spreading could yield the right forms. It is only through the mechanism of pre-association that the correct forms can be produced. Again, our analysis can explain internal gemination by means of constraint interaction between universally attested constraints.

Boudlal (2001), however, analyzes the causative pattern by means of constraint interaction à la OT. At the heart of this analysis is the claim that the causative affix is a reduplicative one. To be more specific, causatives are derived through partially reduplicating the base form (e.g. RED, ktb). The reduplicant is an underspecified segment that copies the features of the segment it is allowed to attach to. The affix is then infixed and takes the features of the second consonant of every root it is affixed to. For a detailed criticism of this analysis, see section 4 below.

\subsection{A root-based approach to causatives}

As far as deriving morphological causatives is concerned, the choice of the base form remains a controversial issue. The main controversy revolves around whether morphological rules apply to words or roots. Two possible hypotheses suggest themselves. Under one hypothesis, causative verbs in MA are derived directly from roots whose syntactic categories and morpho-phonological information are not specified yet, hence the name of the root-based hypothesis. Under the other hypothesis, the base forms of causatives are fully specified words for their syntactic categories and morpho-phonological information such as verbs, nouns and adjectives (Bennis, 1992).

Here, it is argued that a root-based approach to MCs eschews the problems of base-to-output nonconformity and base unavailability (Noamane, 2018a). Such problems, however, are posed by a word-based approach. More specifically, when a word-based approach is adopted, it is shown that (i) some causatives randomly lose some of their bases' phonological material, and (ii) some causatives do not have any word-form corresponding base:

(5) Base nonconformity

\begin{tabular}{|c|c|c|}
\hline morqa & 'broth' & mər?̣əq \\
\hline kura & 'ball' & kəwwar \\
\hline dura & 'circle' & dəwwar \\
\hline rwina & 'mess' & rəwwon \\
\hline
\end{tabular}




\begin{tabular}{|c|c|c|}
\hline ylaf & 'cover' & gallaf \\
\hline tlaq & 'divorce' & tollaq \\
\hline dlala & 'auction' & dallal \\
\hline Sadab & 'torture' & ৎədd $b b$ \\
\hline yawt & 'screaming' & yəwwวt \\
\hline$\hbar a l w a$ & 'candy' & halli \\
\hline jtim & 'orphan' & jəttom \\
\hline șabun & 'soap' & șabbən \\
\hline$f f u \int$ & 'pampering' & $f \partial \iint \partial \int$ \\
\hline
\end{tabular}

(6) Base unavailability

$$
\begin{aligned}
& \text { xəbbi 'to hide' } \\
& \text { rabbi 'to bring up' } \\
& \text { Səllaq 'to hang up' } \\
& \text { wərri 'to show' } \\
& \text { baddal 'to change' } \\
& \text { şawwar 'to take a photo' }
\end{aligned}
$$

In response to this, we believe that a root-based approach allows for a simpler analysis of causatives that is limited to affixing a mora to the root to derive MCs without any further alternations. A theory of roots holds that only idiosyncratic information should be listed in the lexicon, while alternations in derivatives are taken care of by the computational system. Under this conception, causatives are derived directly from their corresponding roots in the lexicon, instead of other surface forms. In this way, perfect correspondence can be established between roots and their corresponding causatives. Also, any causative can be connected with some roots since roots are abstract morphological units.

\section{The prosodic nature of the causative morpheme}

In moraic phonology (Hyman, 1985; McCarthy \& Prince, 1986; Hayes, 1989), the mora is seen as a phonological unit of measuring syllable weight and segmental length. Under this conception, syllables are classified as heavy or light if they consist of two moras or one mora, respectively.

(7) a. Light $\sigma$

$$
\bigwedge_{\mathrm{C}}^{\mathrm{\sigma}}{ }_{\mathrm{V}}^{\mathrm{\sigma}}
$$

$$
\text { b. Heavy } \sigma
$$

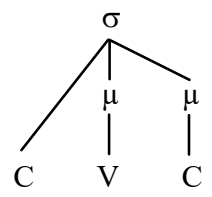

c. Heavy $\sigma$

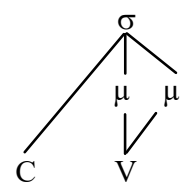

At the segmental level, long vowels are claimed to be underlyingly linked to two moras, whereas short ones have only one. As for long consonants (i.e. geminates), they tend to be 
represented as underlyingly associated with one mora, while singletons are moraless. For illustration, consider (8) below:

(8) a. Vowels

Short Long

Within the realm of moraic theory, Morén $(1999,2003)$ maintains that weight comes in two flavors, namely distinctive and coerced. First, distinctive weight is the result of a lexical specification of moraicity, whereby segments (i.e. vowels and geminates) are underlyingly moraic. Coerced weight, on the other hand, stems from a restriction on surface moraicity in some phonological context. This restriction is imposed by some phonological requirements or rules such as Weight-by-Position (Hayes, 1989). Therefore, distinctive weight includes segments whose moras are underived (i.e. underlying), while coerced weight subsumes segments whose moras are prosodically induced.

Morén's dichotomy implicitly suggests the existence of two types of moras, viz. lexical moras and phonologically induced ones. In MA, for example, geminates represent a case of lexical moras, which are underlyingly linked to a consonantal root node ( $\hbar \boldsymbol{n} a$ 'we' vs

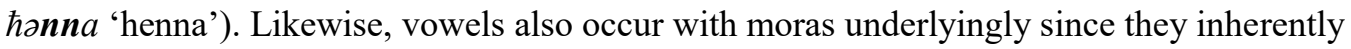
come to function as syllable nuclei. Phonological moras, on the other hand, exist in MA as a result of a requirement on coda consonants to be moraic; hence, they contribute some weight to the syllable. To illustrate, in MA, all closed syllables are heavy since Weight-by-Position takes effect, assigning a mora to every consonant in coda position. For convenience, the rule of Weight-by-Position is schematically depicted in (9) below:

(9)<smiles>O=C(O)C1CCCCC1</smiles><smiles>[3H][Te][V][B]</smiles>
(Condition: o dominates only one mora)

In a related vein, given the data on morphological gemination in general, and causatives in particular, MA stands for a case where moras can be further induced by some morphological requirement on certain derived forms such as causative verbs and agent nouns. Put differently, the mora of the causative is morphologically driven as it performs the role of a morpheme by deriving new forms and expressing a new meaning through adding more weight to the base form. This means that the mora of the causative morpheme is lexical, except it is not associated with any melodic elements.

On this basis, the affix we propose to perform the function of the causative morpheme is a purely prosodic and abstract morpheme, in the sense that it consists of a consonantal mora that is not associated with melodic material underlyingly (Lombardi \& McCarthy, 1991; Samek-Lodovici, 1992; Bensoukas, 2001). Its key role is to create new forms (i.e. 
causatives) by adding some meaning to the base form (i.e. root), namely the meaning of causativity. Furthermore, besides its morphological role as a causative affix, this mora changes the phonological make-up of the base form, causing a geminate in the root. Accordingly, the postulated mora has the following properties:

(i) Morphologically, it plays the role of the causative morpheme.

(ii) Phonologically, it is a prosodic constituent that adds to phonological weight and segmental length.

\section{Against a segmental analysis of morphological gemination}

Our proposal to account for morphological gemination by dint of mora affixation finds further support in previous analyses, namely Lombardi \& McCarthy (1991) and Samek-Lodovici (1992). On the one hand, Lombardi \& McCarthy (1991) argues that the formation of completive verbs in Choctaw, a Muskogean language, calls upon mora prefixation to a circumscribed base à la prosodic circumscription. The affixed mora is then linked to the adjacent consonant by a rule of spreading, hence geminating the affected consonant. Next, the derived geminate occurs word-medially after concatenating the extra-prosodic constituent. On the other hand, Samek-Lodovici (1992) capitalizes on this assumption and extends it to provide a unified analysis of cross-linguistic morphological gemination, using the constraint-based framework of OT. The essence of the analysis presented in this work is that MG in Keley-i and Alabama arises from edge-oriented mora affixation. The optimal output is then decided by the syllable well-formedness constraints of each language.

Other accounts of morphological causatives in MA (see Boudlal, 2001:192) have suggested that the causative formation involves a case of partial reduplication of the base. Based on the nature of each process, the first view would be named the moraic analysis, while the second one is dubbed the segmental analysis. As far as the moraic analysis is concerned, it is believed that gemination stems from the prefixation of a morphologically induced mora, whereby the latter contributes some weight to the affected segment. As for the segmental analysis, gemination is assumed to occur as a result of copying part of the base form, namely the second segment. The two analyses can be schematically illustrated as follows:

(10) a. Moraic analysis

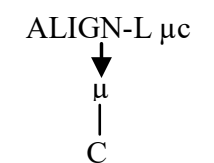

b. Segmental analysis

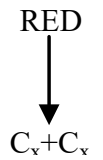

In this section, we outline some of the arguments in support of the moraic analysis and against the segmental analysis. To begin with, both affixation and reduplication are concatenative morphological word formation processes. On the one hand, the role of 


\section{The Morphophonology of Moroccan Arabic Derived Causatives}

affixation consists in adding some extra material to the base form (i.e. bound morpheme). In reduplication, on the other hand, the material added is copied from the base. In this context, two types of reduplication are identified, viz. total reduplication and partial reduplication. The former duplicates the entire base form, whereas the latter copies only some portion of the base.

In the literature, it has been widely assumed, following Marantz (1982), that reduplication is just another type of affixation, whereby the affix is a phonologically skeletal morpheme. This is then followed by copying and associating the segmental content of the base to the affixed template (Inkelas, 2006). By way of illustration, consider the following example from Inkelas (2006:417):

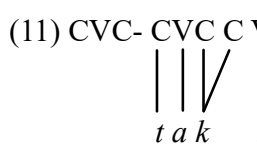

Affixation

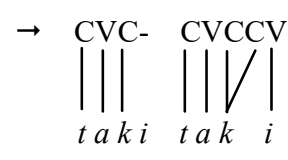

Copy, association

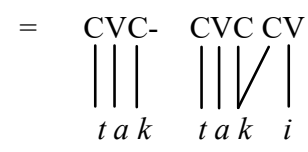

Erasure of unassociated segments

However, even in this case, where reduplication itself is boiled down to affixation, a major distinction is in order between standard affixation (i.e. adding an independent new material) and reduplicative affixation (i.e. copying some of the base material). Such a distinction is endorsed by the fact that natural languages vary in terms of the presence of each process. That is, a language which involves affixation does not necessarily have reduplication. Accordingly, in MA, reduplicative affixation is not as productive as standard affixation, where the latter is more basic and universally less marked. This being the case, speaking of the causative formation, it would be more natural and less marked to opt for standard affixation in order to account for medial gemination in causative verbs.

Besides, the segmental analysis of gemination cannot refer to syllable weight, segmental length and phonological augmentation, and hence does not use the constituents in the prosodic hierarchy, namely the concept of mora. Instead, a segmental analysis would resort to the counting of segments to represent weight and length. However, according to Hayes (1989), the segmental analysis has proven to be inadequate to explain another phenomenon, more specifically, Compensatory Lengthening (CL). CL can be defined as a phonological process in which a segment undergoes lengthening due to the elision or shortening of an adjacent segment. Usually, it is a vowel which lengthens, triggered by the deletion of a coda consonant. Part of the criticism is that, as Hayes (1989:254) puts it, "any segment can lengthen to compensate for the loss of any other segment", whereas this goes against the fact that many languages lack CL with the presence of the same conditions that trigger it elsewhere. For this reason, Hayes maintains that there is a need for a language-specific parameter to capture such a cross-linguistic variation. This can only be possible under a moraic analysis of $\mathrm{CL}$, in the sense that only languages where a syllable coda is moraic can 
give rise to $\mathrm{CL}$, as represented in (12):

(12) Compensatory Lengthening in Moraic Phonology:

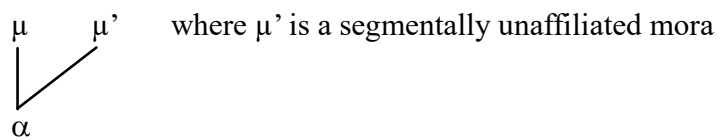

In later versions of the theory of prosodic morphology, namely templatic morphology (McCarthy \& Prince, 1986, 1990a, 1990b), restrictions on the size and shape of morphological constituents (i.e. affix, stem, root, word) are defined in prosodic terms, viz. phonological word, foot, syllable and mora. On this view, as far as reduplication is concerned, the reduplicative morpheme must be stated as a prosodic constituent. As a consequence, the case of morphological gemination involved in causatives poses a problem to the prosodic analysis of reduplication in that it does not refer to a constituent from the prosodic hierarchy. In other words, it is not possible to consider morphological gemination as a result of segment duplication since a segment is obviously not a prosodic constituent. Hence, consistently with the tenets and principles of prosodic theory, which necessitate reference to prosodic constituents, it is less costly to sacrifice the morphological process of reduplication and replace it by affixation, rather than to change the essence of the theory by attributing a prosodic status to segments, especially since the use of affixation allows for reference to a prosodic constituent (i.e. mora) in total compliance with the premises of prosodic theory.

\section{Mora affixation as alignment}

Anchor constraints are one of Prince \& Smolensky's (2004) earliest contributions in OT. Similarly, McCarthy \& Prince (1993b) proposes a general family of constraints to capture the various constituent-edge effects in both morphology and phonology. Linguistic theory provides the grammar with a wide range of prosodic (PCat) and grammatical (GCat) categories. Thus, a Generalized Alignment (GA) requirement "demands that a designated edge of each prosodic or morphological constituent of type Cat1 coincide with a designated edge of some other prosodic or morphological constituent Cat2" (See McCarthy \& Prince, 1993b:2). The general schema of this constraint family comes as follows:

(13) Generalized Alignment: (McCarthy \& Prince, 1993b)

Align (Cat1, Edge1, Cat2, Edge2) $=_{\text {def }}$

$\forall$ Cat $1 \exists$ Cat 2 such that Edge 1 of Cat1 and Edge 2 of Cat 2 coincide

Where

Cat 1, Cat $2 \in$ PCat $\cup$ GCat

Edge1, Edge2 $\in$ \{Right, Left $\}$

Of close relevance to GA are two principles. First, GA comprises diverse operations and 


\section{The Morphophonology of Moroccan Arabic Derived Causatives}

procedures that have nothing in common. Consequently, the generality of this theory can be possible only in a constraint-based system like OT. Second, alignment constraints can be violated minimally. However, the affix should be as close as possible to the designated edge. Therefore, alignment constraints need to be gradiently assessed for violations, whereby the degree or multiplicity of violation is measured in terms of distance from the designated edge. The formal constraint which represents this general family is ALIGN, which can then be specified for the designated edges and the relevant categories.

One of the major functions of ALIGN constraints is the formation of new words by affixing morphemes to the left or the right of a stem. GA conceives of affixation as an edge-oriented phenomenon. Under this model, no affixal status is attributed to morphemes. Instead, their prefixhood or suffixhood is dictated by a constraint on output well-formedness (Ussishkin, 2007). In this context, prefixation and suffixation occur when ALIGN constraints refer to the left edge and the right edge, respectively.

As far as our analysis is concerned, we hypothesize that causative formation in MA involves an alignment constraint specified as follows: ALIGN ( $\mu_{\mathrm{c}}$, Left, Root, Left). This constraint is defined in (14) below:

(14) ALIGN ( $\mu_{\mathrm{c}}$, Left, Root, Left)

The left edge of the consonantal mora (PCat) must coincide with the left edge of the root (GCat).

This constraint requires that the left edge of the affix morpheme $/ \mu_{d} /$, which is an abstract morpheme that refers to a consonantal mora, coincide with the left edge of some root, resulting in the prefixation of the affix. The outcome of this process is the derivation of causative verbs. For instance, given a root form like /tll/ 'snow', ALIGN $\left(\mu_{\mathrm{c}}\right.$, Left, Root, Left) places a consonantal mora $\left(\mu_{\mathrm{c}}\right)$ at its left edge for the sake of deriving the causative verb talloz 'to make snow', as depicted in (15) where brackets refer to the edge of a constituent.

(15) Root tl3

$$
\begin{array}{cc}
\text { Affix } & \text { Alignment (Root }+ \text { Affix) } \\
\mu_{c} & {\left[\mu_{c}\left[t l_{3}\right]\right]}
\end{array}
$$

Otherwise, if the purported affix is aligned to an edge other than the left edge, say the right one, this constraint would be violated, as displayed in the illustrative incomplete table below:

Table 1. Mora affixation as alignment

\begin{tabular}{c|c}
\hline$\mu_{c} \sqrt{ } t l_{3}$ & $\operatorname{ALIGN}\left(\mu_{\mathrm{c}}, \mathrm{L}\right.$, Root, L $)$ \\
\hline a. $\left[\mu_{c}\left[t l_{3}\right]\right]$ & Satisfied \\
\hline b. $\left[t l_{3}\left[\mu_{c}\right]\right]$ & Violated \\
\hline
\end{tabular}




\section{Positional faithfulness}

The analysis proposed in this paper relies crucially on the concept of positional faithfulness (Beckman, 1998). In this approach, certain linguistic positions are characterized as being privileged in comparison with other non-privileged positions. As noted by Beckman (1998:1), "privileged positions are those positions which enjoy some perceptual advantage in the processing system, via either psycholinguistic or phonetic prominence." For illustration purposes, the inventory that Beckman has established of privileged positions and their non-privileged counterparts is reproduced here:

$\begin{array}{ll}\text { (16) a. Privileged positions } & \text { b. Non-privileged positions } \\ \text { Root-initial syllables } & \text { Non-initial syllables } \\ \text { Stressed syllables } & \text { Unstressed syllables } \\ \text { Syllable onsets } & \text { Syllable codas } \\ \text { Roots } & \text { Affixes, clitics } \\ \text { Long vowels } & \text { function words } \\ & \text { Short vowels }\end{array}$

As Beckman suggests, positional privilege and prominence can be determined on phonological grounds. To this end, Beckman identifies three distinct diagnostic criteria of positional privilege. First, it is believed that privileged positions are characterized by positional maintenance of segmental or featural contrasts which are neutralized in non-prominent positions. Second, segments in these positions are said to trigger phonological processes such as assimilation and dissimilation. Third, such positions also tend to resist phonological processes that apply elsewhere.

In OT terms, each of the above-mentioned phonological asymmetries arises whenever positional faithfulness constraints dominate context-free faithfulness and markedness constraints. This constraint interaction is formally formulated in (17), where F stands for any phonological feature and $\mathrm{C}$ represents the constraint which affects the distribution of $\mathrm{F}$ :

(17) Ranking schema, positional phonological asymmetries (Beckman, 1998:9)

IDENT-Position (F) >> C >> IDENT (F)

In this model, positional faithfulness constraints stipulate that segments in privileged positions should be identical with their corresponding underlying segments feature-wise. The general schema of this type of constraints is provided in (18) below:

(18) IDENT-Position (F) (Beckman, 1998)

Let $\beta$ be an output segment in a privileged position $P$ and $\alpha$ the input correspondent of $\beta$. If $\beta$ is $[\gamma \mathrm{F}]$, then $\alpha$ must be $[\gamma \mathrm{F}]$.

"Correspondent segments in a privileged position must have identical specifications for [F]."

The relevance of this to the analysis advanced herein comes as follows. The causative morpheme, represented by the consonantal mora, never affects the left edge of the root. 


\section{The Morphophonology of Moroccan Arabic Derived Causatives}

Rather, the phonological manifestation of this morpheme is realized on the second segment of the root. This happens despite the fact that affixation is conceived of as an edge-oriented phenomenon whereby affixes either appear at the left or the right edge of the stem. In fact, it has been demonstrated that the consonantal mora, indicating the posited affix, is aligned to the left edge of the root. Hence, it is supposed that the first segment of the root should geminate rather than the second one. To take an example, given the root $ل_{f z g}$ 'wet', the alignment constraint (i.e. ALIGN- $\left(\mu_{\mathrm{c}}, \mathrm{L}\right.$, Root, $\left.\left.\mathrm{L}\right)\right)$ requires that the mora be prefixed to this root to derive the causative form. Being a prosodic unit of weight, the mora lengthens the segment it attaches to. The predicted form so far is the causative verb *ffzzag. Nevertheless, a form like this is ill-formed and ungrammatical as it never appears as a causative verb in MA. More precisely, causatives never occur with their first segments geminated. In other words, initial-root segments preserve their prosodic specification for weight in surface forms.

With this in mind, in this section, we argue for the root-initial segment as a privileged position in MA. This fact can elucidate why root-initial segments do not undergo lengthening, even though they are targeted by a morphological rule of affixation. Extending this view, we show that this position meets the diagnostic criteria put forth by Beckman (1998), and marks off prominent positions from non-prominent ones. To begin with, as far as the maintenance of segmental and featural contrast is concerned, the root-initial segments involved in causative formation tend to maintain their underlying prosodic specification for weight. That is, all the segments occupying the left edge of the root match their correspondents in causative forms prosody-wise.

Second, as is apparent, root-initial segments always resist and block the application of the morphological process of affixation. The domain of application of the alignment constraint is specified as the left edge where initial segments are located. However, due to its prominent status, this demand on surface forms is blocked. Note that the resistance of gemination in this case has nothing to do with the feature composition of the segment itself since gemination fails to apply only when the target segment is contained in the initial position of the root. For instance, consonants like $/ \mathrm{k} / \mathrm{t} / \mathrm{t} /$ and $/ 1 /$ do not geminate in the causatives $k a t t a b$ 'to cause someone to write', tajjab 'to cook', la५५ab 'to make someone play' solely when they occur root-initially in $\sqrt{ } k t b, \sqrt{t} i b$ and $\sqrt{ } l \varsigma b$, respectively. However, the same consonants get geminated in causatives like rəkkab 'to make someone ride', rattab

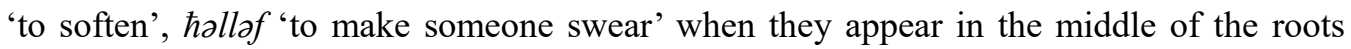
$\sqrt{ } r k b, \sqrt{ } r t b$ and $\sqrt{ } \hbar l f$.

The third phonological diagnostic assessment of positional privilege is the triggering of processes. Root-initial segments involved in causative derivation do not serve as triggers of phonological processes. Still, evidence for this property can be brought from other related 
phenomena, namely the process of assimilation which takes place between the definite article affix /1+/ and word-initial coronal sounds, as shown in (19):

(19) Positional faithfulness in MA:

\begin{tabular}{|c|c|c|}
\hline /1-sma/ & ssma & 'the sky' \\
\hline /1-nas/ & nnas & 'people' \\
\hline /1-nSas/ & $\boldsymbol{n} n$ Sas & 'sleeping' \\
\hline /1-ṛbic/ & rgrbis & 'the grass' \\
\hline
\end{tabular}

Originally, the data is used to argue for root faithfulness in general, whereby it is the whole root which is seen as a privileged position that simultaneously blocks and triggers a process of total assimilation. Similarly, on the basis of these items, one could also claim that it is a case where it is precisely the root-initial segment which triggers assimilation with the definite article, especially that the shared features are contributed by this particular position.

Upon further investigation, it turns out, as noted before, that this is not a case of root faithfulness altogether. It follows that, in MA, roots are not fully immune to phonological and morphological processes. More specifically, root-final and root-medial segments are prone to phonological alternation like in the case of causative derivation, whereby root-medial segments get geminated (e.g. $\sqrt{ } k t b \rightarrow k a t t a b)$ or in the case of the first person singular morpheme suffixation in which root -final segments get assimilated (e.g. /mred-t/ $\rightarrow m r a t t)$. It remains that the only position which is consistently privileged over the others is the root-initial segment. The latter resists the application of processes on two occasions. First, as far as causatives are concerned, it blocks the application of morphological gemination (i.e. ALIGN-L $\left(\mu_{c}, R\right)$ ). Second, in the case of the definite article $/ 1+1$ prefixation, it blocks the application of assimilation (i.e. AGREE-Coronal).

With this done, we can now argue that there is a positional faithfulness constraint on output well-formedness that ensures the maintenance of the underlying specification for the weight of root-initial segments in surface forms. In this context, since it is only a specific element which is at stake, the general constraint family involved is IDENT-(F), where F stands for any phonological feature. Yet, under the realm of positional faithfulness, featural identity is context sensitive, whereby corresponding segments belong to a specific privileged position. As a result, such a constraint will be assigned the following formal shape: IDENT- $\mathrm{C}_{1}$-Weight - where $\mathrm{C}_{1}$ refers to the root-initial consonant:

\section{(20) IDENT-C $\mathrm{C}_{1}$-Weight}

"Correspondent segments in the initial-root position must have identical specifications for [weight]."

For it to be enforced across the board, this constraint should be higher-ranked and undominated. Therefore, in the case of causatives, it is believed that IDENT- $\mathrm{C}_{1}$-Weight emerges to be dominant over ALIGN ( $\mu_{\mathrm{c}}, \mathrm{L}$, Root, L). As a matter of fact, being ranked in 
this way, positional faithfulness will prevail across the causative data, in the sense that the weight of root-initial segments will not be altered.

(21) Positional privilege ranking schema, initial-root segments IDENT-C $_{1}$-Weight $>>$ ALIGN-L $\left(\mu_{c}\right.$, Rt)

The cost of satisfying this positional requirement is the violation of the ALIGN constraint, which is ranked lower. IDENT- $\mathrm{C}_{1}$-Weight is violated whenever root-initial segments appear as geminates in surface forms, as depicted in the following illustrative table:

Table 2. Positional faithfulness

\begin{tabular}{c|c}
\hline$\mu_{c} \sqrt{ } l \varsigma b$ & IDENT-C $_{1}$-Weight \\
\hline a. $l \partial \varsigma \zeta \partial b$ & Satisfied \\
\hline b. $l l \varsigma \partial b$ & Violated \\
\hline
\end{tabular}

A criticism of an earlier version of our positional faithfulness analysis of the causative morpheme infixation (Noamane, 2013/2014) was put forward by Loutfi (2017). The criticism is two-fold. Theoretically, the author claims that our positional faithfulness does not comply with the meta-constraint ranking of Beckman (1998). Empirically, however, Loutfi (2017) does not recognize the privileged status of the initial root segment to be due to the latter's susceptibility to change in other contexts, citing data from Zellou (2010) pertaining to labial assimilation and long-distance consonant harmony. The fact is that both of these points are, to say the least, based on a rushed judgement; hence, they are unable to undermine our analysis. First, positional faithfulness constraints can and do occur independently. They simply represent a type of context dependent faithfulness whereby a specific position or grammatical category does not succumb to general alternations due to perceptual and productive psycholinguistic limitations (Nooteboom, 1981). This creates a categorical asymmetry between positions which can be depicted by ranking the context-dependent faithfulness constraints above the context-free ones (Beckman, 1997). In our case, the positional asymmetry is represented by ranking the context-dependent faithfulness constraint IDENT-W-C1 above the context-free faithfulness constraint IDENT-W (i.e. IDENT-C1-W >> IDENT-W).

Second, it should be understood that the premise of positional faithfulness is not based on absoluteness. Therefore, the examples of labial assimilation and consonant harmony that involve changing some of the features of the first consonant do not prove or, in this case, disprove any point, especially that the data referred to is inconclusive (e.g. foms-fəmf 'sun'). Rather, privileged positions are only relatively privileged in relation to less privileged ones. This means that as long as initial root consonants systemically exhibit some degree of prominence, which other consonants lack, they can be qualified as a privileged position. 
What else, the relevant assimilatory processes occur within the root material whereas the question should be whether root segments resist or trigger processes from outside of the root. This is the only way we can establish asymmetry between root and affix faithfulness. This is exactly what we observe in the case of total assimilation between the definite article and coronal initial nouns, whereby the prominence of $\mathrm{C}_{1}$ determines the direction of the assimilation process by resisting featural change and imposing its features on the definite affix. In the case of labial assimilation, rounding seems to affect the whole word and does not single out the initial consonant (e.g. $x^{w} r^{w} u 3^{w}$ 'going out'). Therefore, it is safe to generalize this prominence to account for the misalignment of the moraic morpheme in derived causatives.

Moreover, the alternative analysis proposed in Loutfi (2017), whereby the markedness constraint *COMPLEX-ONSET is responsible for the misalignment of the moraic causative affix, misses the point. In MA, complex margins can be consistently avoided by creating syllabic consonants, such that a cluster or a geminate would span over two syllables. Given this fact about MA phonology, it would be redundant and unnecessary to claim that the language would resort to infixation to obviate a complex onset.

\subsection{Morpheme position}

Now, the question is what happens to the causative affix after being deprived of aligning to the designated left edge. By mere observation, we notice that all causative verbs encompass geminates in the middle, which differ from their corresponding root segments in terms of weight (or length). Here, our main claim is that the causative affix is misaligned; hence, infixation is imposed. In so hypothesizing, root-medial segments geminate due to the misaligned consonantal mora. Another pertinent question is what causes the misalignment of the causative morpheme, or what forces the infixation of this morpheme.

As reported by Ussishkin (2007), affixes are shown to come in two flavors: prefixes or suffixes. By assumption, prefixes are placed at the left edge of stems, while suffixes emerge at the right edge of stems. This is grounded on the conception put forward by Generalized Alignment (McCarthy \& Prince, 1993b) whereby affixation is an edge-oriented phenomenon. Nonetheless, it is very likely that affixes occur in positions other than the edge. For instance, an affix may split a morpheme and get inserted inside it. An oft-cited example is the Tagalog affix -um-. This affix functions as an agentive focus marker and may appear at the left edge of a stem or inside it. At first blush, it seems that we are facing a specific and independent type of affixes, identified with infixes. As a response, GA significantly proves that "when affixes occur anywhere other than the edge of a word, phonological pressures are always responsible" (Ussishkin, 2007:457). This indicates that infixation is a mere phonological phenomenon rather than a morphological one. To elaborate this thesis further, Ussishkin maintains that morpheme or affix position in the 
case of infixation is phonologically driven and is determined by well-formedness requirements on surface forms.

Under an OT alignment-based account, the position of the causative morpheme is determined by the constraint ALIGN-L $\left(\mu_{\mathrm{c}}, \mathrm{Rt}\right)$, which requires that the left edge of the causative morpheme coincide with the left edge of the root. However, due to some phonological restrictions on output forms, infixation of the consonantal mora is forced. In particular, what forces infixation in causatives is the constraint IDENT-C I $_{1}$-Weight, which represents the positional privilege that root-initial segments enjoy. In other words, being high-ranked, IDENT- $\mathrm{C}_{1}$-Weight bans prefixation from taking place and turns it into infixation. This can be expressed as follows, where the same schema used to illustrate positional privilege in (17) is now employed to elucidate how misalignment occurs:

(22) Positional faithfulness forces violation of alignment:

IDENT-C $_{1}$-Weight $>>$ ALIGN-L $\left(\mu_{\mathrm{c}}, \mathrm{Rt}\right)$

In this paper, the explanation for why the process of germination invariably targets the second consonant of the root is purely psycholinguistic. This means that we are simply claiming that root initial segments tend to preserve their identity because they are somehow more privileged. If we would like to dig deeper, we can attribute the privileged status of root initial segments to phonological restrictions. So, what could those restrictions be? One possible explanation might be that the phonological system of MA does not approve word-initial geminates. This in itself could be because geminates are moraic, which risks having moraic onsets, or doubled, which may give rise to complex onsets (see Noamane (2018b, 2019, 2020) for more on geminate representation and behavior in MA). However, MA is well-equipped to deal with both scenarios. If geminates are moraic, the mora of the geminate can project its own syllable since minor syllables are very common in MA (Boudlal, 2001). On the other hand, if geminates are seen as doubled structures, the first half of the geminate can also project its own syllable, creating a minor syllable. This means that initial geminates in MA are not a problem, especially that they are productively derived elsewhere (e.g. definite article total assimilation). Nevertheless, we can argue that MA prefers to minimize its overreliance on minor syllables. Hence, it resorts to infixation whenever that is possible (for a better articulation of phonologically-driven infixation in MA, see Noamane (2018c)). Therefore, the infixation of the causative mora could be seen as a strategy to avoid creating more minor syllables in MA.

One last fact is that infixation itself is an edge-oriented phenomenon, whereby the affix occurs as close as possible to the designated edge. The more misaligned the affix, the more punished by the alignment constraint in a gradient fashion, as is shown in the following table: 
Ayoub Noamane

Table 3. Morpheme position

\begin{tabular}{|c|c|}
\hline$\mu_{c} \sqrt{ } n S_{S}$ & ALIGN-L $\left(\mu_{\mathrm{c}}, \mathrm{Rt}\right)$ \\
\hline a. $n n$ Cos & Satisfied \\
\hline 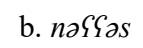 & $*$ \\
\hline c. $n$ GəSS & $* * !$ \\
\hline
\end{tabular}

\subsection{Why not right alignment?}

So far, it has been assumed that the position of the causative affix is determined by dint of the process of prefixation, represented by the constraint ALIGN-L, in interaction with positional faithfulness. Up to this point, we have not explained yet why suffixation is being discarded or, in OT terms, why alignment does not refer to the right edge of the root. Now that the concept of positional faithfulness has been made clear, we can advance our argument in this regard. At first blush, it seems that suffixation could do the same job as prefixation. It appears that it is possible to align the causative affix to the right edge of the root and then account for the occurring misalignment in much the same way as we did with prefixation. However, this is far from being feasible taking into consideration the non-privileged status of the root-final segments. As stated earlier, root-final segments are subject to alternation by a process of assimilation with the first person singular suffix - $t$. As a consequence, in case the postulated mora is aligned to the right, there would be no phonological pressure on output well-formedness to force the infixation of this affix and preserve the identity of the root-final segment, giving rise to unattested forms in MA such as $*_{\text {zzagg }}{ }^{*} n$ Cass and $*$ tlaz̧.

\section{Realizational Morphology Theory (RMT)}

OT Realizational Morphology is a formal theory developed by Kurisu (2001) to provide a comprehensive understanding of how morphemes are phonologically manifested both in concatenative and non-concatenative morphology. In concatenative morphology, meaning is built upon the sequential agglutination of distinct morphemes. In non-concatenative morphology, on the other hand, morphemes cannot be sequentially demarcated. Thus, RMT is principally concerned with how non-concatenative morphological operations such as umlaut, suppletion and mutation are to be accounted for.

The theory also distinguishes between purely phonological alternations and morphologically motivated ones. In OT terms, the former kind of alternations is accounted for in terms of the basic markedness and faithfulness constraints. The latter, however, is motivated by RM being dominant over phonological faithfulness constraints (i.e. $\mathrm{RM}>>$ Faith) since in this case it is sensitive to some morphological information. 
Consequently, faithfulness violations involved in nonconcatenative morphology are not the result of phonological conditioning (i.e. Markedness $>>$ faithfulness). Rather, they are driven by morphological requirements about the presence of a morpheme in output representations. This indicates that nonconcatenative morphology displays anti-faithfulness effects to be distinguished from faithfulness violations observed in standard phonology.

This theory proposes a Realize Morpheme constraint (RM) to capture the phonological realization of underlying abstract morphemes in nonconcatenative morphology. RM forces every underlying morpheme to receive some phonological property (not necessarily phonological substance) in output forms. Besides, this constraint is satisfied if and only if the candidate does not perfectly match the input form, where phonological discrepancy is exactly what denotes morphological contrasts. RM can be formulated as in (23):

(23) Realize Morpheme (RM) (Kurisu, 2001:39)

Let $\alpha$ be a morphological form, $\beta$ be a morphosyntactic category, and $F(\alpha)$ be the phonological form from which $\mathrm{F}(\alpha+\beta)$ is derived to express a morphosyntactic category $\beta$. Then RM is satisfied with respect to $\beta$ iff $F(\alpha+\beta) \neq F(\alpha)$ phonologically.

In the case of causative formation in MA, roots serve as the basis of their corresponding causative verb forms. As a result, the root and the causative verb correspond to a morphological form $(\alpha)$ and a morphosyntactic category $(\beta)$, respectively. $/ \mathrm{ktb} /$ root and $k a t t a b$ causative are phonologically non-identical because the causative verb form involves a medial geminate which is not observed in the root. With this background in hand, we can formulate the RM constraint for causatives as follows:

(24) RM, causative verbs in MA

The causative morpheme must have some phonological exponence in the output form, whereby the latter should be unfaithful to the root.

This means that the underlying causative verb morpheme is phonologically manifested by virtue of receiving a phonological exponence in the output form kattab causative, hence RM is satisfied. Otherwise, a possible candidate which is totally faithful to the input, say * $k t a b$, violates RM. This can be visually demonstrated in the following incomplete table:

Table 4. Realize morpheme

\begin{tabular}{c|c}
\hline$\mu_{c} \sqrt{ } k t b$ & $\mathrm{RM}$ \\
\hline a. $k \partial t t a b$ & Satisfied \\
\hline b. $k t \partial b$ & Violated \\
\hline
\end{tabular}

The role of RM is confined to maintaining morphological contrasts by imposing some phonological manifestation of underlying morphemes without specifying how these morphemes are realized. In this model, the specific morpheme realization is determined by the faithfulness constraint ranked below RM. Concerning the case of causatives in MA, the 
realization of the causative morpheme is dictated by RM, whereas its identity is determined by the low ranked faithfulness constraint IDENT-IO (Weight). For convenience, the general schema of IDENT constraints is given in (25) below (McCarthy \& Prince, 1995:16):

(25) The IDENT (F) Constraint Family

General Schema

IDENT (F): Let $\alpha$ be a segment in S1 and $\beta$ be any correspondent of $\alpha$ in S2.

If $\alpha$ is $[\gamma \mathrm{F}]$, then $\beta$ is $[\gamma \mathrm{F}]$. (Correspondent segments are identical in feature $F$ ).

Specific Instantiations

IDENT-BR (F): Reduplicant correspondents of a base $[\gamma \mathrm{F}]$ segment are also $[\gamma \mathrm{F}]$.

IDENT-IO (F): Output correspondents of an input $[\gamma \mathrm{F}]$ segment are also $[\gamma \mathrm{F}]$.

The ranking of RM over IDENT-IO (Weight) indicates that the optimal form could incur some violation of IDENT-IO (Weight), hence the realization of the causative morpheme. Other details about how and where the morpheme is realized are determined by other constraints in the hierarchy, notably IDENT-RtC1 (Weight) and ALIGN- ( $\mu \mathrm{c}, \mathrm{L}$, Root, L).

After having presented the relevant constraints along with their theoretical background in an incremental and detailed way, we intend to show, in the subsequent section, how these constraints together with their ranking lead to the formation of causative verbs.

\section{Constraint interaction}

To recapitulate, cast in the constraint-based framework of OT, the analysis defended herein is underlain by the basic idea that there are four major constraints responsible for the formation of morphological causative verbs in MA. RM is an anti-faithfulness constraint which stipulates that some phonological exponence must be manifested in the output form for the sake of realizing the causative morpheme. This constraint prohibits perfect matching between the input (i.e. root) and the output (i.e. causative); it is satisfied only when there is some phonological discrepancy between them.

The Second constraint, IDENT-IO (Weight), is a faithfulness constraint which requires corresponding output and input segments to be identical in terms of weight. As a result, this constraint disallows input segments from gaining more length or weight as they occur in output forms. Third, ALIGN-L $\left(\mu_{\mathrm{c}}, \mathrm{Rt}\right)$, is an alignment constraint that demands coincidence between the left edge of the causative affix (i.e. mora) and the left edge of the root. Given this demand, ALIGN-L $\left(\mu_{c}, \mathrm{Rt}\right)$ is violated whenever the edges of the specified constituents fail to coincide. Fourth, IDENT- $\mathrm{C}_{1}$-Weight is a constraint on positional faithfulness which ensures that feature specification for the length of the root-initial segment is preserved in output forms. This constraint militates against any alteration of length at the level of the first radical element. These are summarized below:

(26) Constraints responsible for deriving morphological causatives in MA: 
a. ALIGN- ( $\boldsymbol{\mu}_{\mathrm{c}}$, Left, Root, Left): The left edge of the causative morpheme must coincide with the left edge of the root.

b. RM: Some phonological exponent must appear in the output form.

c. IDENT-C $\mathbf{C}_{\mathbf{1}}$-Weight: The featural specification for the weight of the root's first radical element must be preserved in the input/output mapping.

d. IDENT-IO (Weight): Output segments and Input segments must be featurally identical for weight.

We proceed by putting forward the appropriate ranking that would yield the expected output forms. In particular, we highlight the existing ranking arguments between the constraints at play. Ranking arguments will provide us with evidence for ranking certain constraints over others or leaving them unranked.

First, Table 5 compares the winning candidate $k a t t a b$ with the losing candidate *ktab, whereby the former satisfies RM and violates IDENT-IO (Weight), and the latter violates RM and satisfies IDENT-IO (Weight). This shows that these constraints do really have conflicting demands. Consequently, RM is ranked high because it favors the winning candidate while IDENT-IO (Weight) is ranked low as it favors the loser.

Table 5. Ranking argument (1): RM >> IDENT-IO (Weight)

\begin{tabular}{c|c|c}
\hline$\mu_{c} \sqrt{ } k t b$ & $\mathrm{RM}$ & IDENT-IO (Weight) \\
\hline a. $k$ $k t t \partial b$ & & $*$ \\
\hline b. $k t \partial b$ & $* !$ & \\
\hline
\end{tabular}

Second, Table 6 displays a conflict between IDENT- $\mathrm{C}_{1}$-Weight and ALIGN-L $\left(\mu_{\mathrm{c}}, \mathrm{Rt}\right)$ as they disagree on the assessment of both the winner and the loser. Since IDENT- $\mathrm{C}_{1}$-Weight appears to favor the winning candidate, it ranks high in the hierarchy above ALIGN-L ( $\mu_{c}$, Rt).

Table 6. Ranking argument (2): IDENT-C I $_{1}$ Weight $>>\operatorname{ALIGN-L~}\left(\mu_{\mathrm{c}}, \mathrm{Rt}\right)$

\begin{tabular}{c|c|c}
\hline$\mu_{c} \sqrt{k t b}$ & IDENT-C $_{1}$-Weight & ALIGN-L $\left(\mu_{\mathrm{c}}, \mathrm{Rt}\right)$ \\
\hline a. $k a t t a b$ & & $*$ \\
\hline b. $k k t a b$ & $* !$ & \\
\hline
\end{tabular}

Third, Table 7 demonstrates a conflict between IDENT-C ${ }_{1}-\mathrm{W}$ and IDENT-IO (Weight) since they exhibit a disagreement on the assessment of the optimal form.

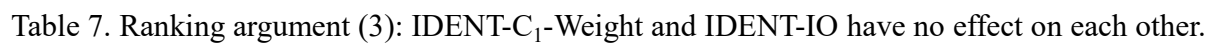

\begin{tabular}{c|c|c}
\hline$\mu_{c} \sqrt{ } k t b$ & IDENT-C $_{1}$-Weight & IDENT-IO (Weight) \\
\hline a. $k a t t a b$ & & $*$ \\
\hline b. $k k t a b$ & $* !$ & $*$ \\
\hline
\end{tabular}


However, Table 8 shows us that the relevant constraints agree on the assessment of at least one candidate which means that they do not conflict or dominate each other. As a result, these constraints will be left unranked in respect to each other.

Table 8. No ranking argument: RM and ALIGN-L $\left(\mu_{c}\right.$, Rt) have no effect on each other.

\begin{tabular}{c|c|c}
\hline$\mu_{c} \sqrt{ } k t b$ & RM & ALIGN-L $\left(\mu_{c}, \mathrm{Rt}\right)$ \\
\hline a. $k a t t a b$ & & $*$ \\
\hline b. $k k t a b$ & & \\
\hline
\end{tabular}

What these rankings are telling us is that there is no one absolute ordering between every pair of our constraints. Rather, the constraint set consists of two dependent ranked sets in the same hierarchy whereby output forms are evaluated by each in a parallel fashion. This can be graphically illustrated by the following Hasse diagram:

(27) Ranking summary for causatives in MA

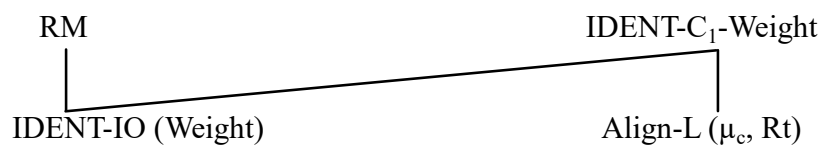

An important fact about OT is that no ranking should be enforced between two constraints where there is no evidence for that. Also, it is not necessary to provide a total ordering of the relevant constraints. A constraint may stay unranked in relation to some other constraint, or it may have no ordering relation at all with another constraint, as far as they agree on the assessment of the winning candidate. As noted by McCarthy (2008:43), "it's perfectly OK if the process of analysis leads to a partial ordering: CONST1 and CONST3 both dominate CONST2, but the ranking between CONST1 and CONST2 is unknown." In this case, only the crucial constraint rankings that are important for the analysis should be determined and highlighted.

Accordingly, the interaction of the constraints and the selection of the optimal form is illustrated in the following table:

Table 9. RM >> IDENT-IO (Weight); IDENT-RtC1 (Weight) $>>$ ALIGN-L ( $\mu_{\mathrm{c}}, \mathrm{Rt}$ )

\begin{tabular}{c|c:c|c:c}
\hline$\mu_{c} \sqrt{ } k t b$ & RM & IDENT-C 1 -Weight & IDENT-IO (Weight) & ALIGN-L( $\left.\mu_{\mathrm{c}}, \mathrm{Rt}\right)$ \\
\hline a. $k a t t a b$ & & $*$ & $*$ & $*$ \\
\hline b. $k t a b$ & $* !$ & $* !$ & $*$ & $*$ \\
\hline c. $k k t a b$ & & $*$ & $*$ & \\
\hline d. $k t a b b$ & & & & $*$ \\
\hline
\end{tabular}

Candidate (a), is morpho-phonologically unfaithful to the input, hence satisfying the high-ranked constraint RM. The same candidate obeys the demand made by the other 
equally high-ranked constraint, IDENT- $\mathrm{C}_{1}$-Weight, by preserving the feature specification for weight of the input's initial segment. Candidate (b), on the other hand, incurs a fatal violation of RM since it includes no phonological exponence to realize the causative morpheme, and thus fails to surface as an output form. As for candidate (c), it is excluded by IDENT-C $\mathrm{C}_{1}$-Weight as it fatally violates the positional faithfulness requirement made by it. In particular, candidate (c) has an initial geminate that does not correspond with the original initial singleton in the root. Finally, candidate (d) ties with the optimal output at the level of the high-ranked constraints. In this case, we are required to go down the hierarchy and look for a possible constraint to untie these candidates.

In the process of doing so, we notice that both candidates incur some violation of the remaining constraints: Align-L $\left(\mu_{\mathrm{c}}, \mathrm{Rt}\right)$ and IDENT-IO (Weight). By resorting to gradient assessment, which alignment constraints allow, we can break such a deadlock. Candidate (d) incurs multiple violations of ALIGN-L $\left(\mu_{c}, R t\right)$, and hence fares worse than the optimal candidate on this constraint. Therefore, as candidate (d) is ruled out, candidate (a) wins out.

In support of our constraint ranking, we demonstrate the possible repercussions that can emerge if the ranking suggested is altered. The re-ranking of faithfulness over anti-faithfulness in Table 10 yields only forms that are fully faithful to the input, while the re-ranking of alignment over positional faithfulness in Table 11 gives rise to forms with initial geminates. In each case, the winning candidates are not attested as causative verbs in MA. Conventionally, the symbol "

Table 10. IDENT-IO (weight) $>>$ RM

\begin{tabular}{|c|c|c|c|c|c|}
\hline$\mu_{\mathrm{c}} \sqrt{k t b}$ & IDENT-IO (Weight) & $\mathrm{RM}$ & \multicolumn{2}{|c|}{ IDENT-C $_{1}$-Weight } & $\operatorname{ALIGN}-\mathrm{L}\left(\mu_{\mathrm{c}}, \mathrm{Rt}\right)$ \\
\hline a. kattab & $* !$ & & & & $*$ \\
\hline$\approx$ b. $k t a b$ & & * & & & \\
\hline c. $k k t ə b$ & $* !$ & & & & \\
\hline d. $k t a b b$ & $* !$ & & & & ** \\
\hline \multicolumn{6}{|c|}{ Table 11. ALIGN-L $(\mu \mathrm{c}, \mathrm{R})>>$ IDENT-C1-Weight } \\
\hline$\mu_{c} \sqrt{k t b}$ & $\operatorname{ALIGN-L}\left(\mu_{\mathrm{c}}, \mathrm{Rt}\right)$ & \multicolumn{2}{|c|}{ IDENT-C $_{1}$-Weight } & $\mathrm{RM}$ & IDENT-IO (Weight) \\
\hline a. $k \partial t t a b$ & $* !$ & & & & $*$ \\
\hline b. $k t a b$ & & & & $*$ & \\
\hline$\widetilde{\sigma} \mathrm{c} k k t a b$ & & & & & $*$ \\
\hline d. $k t a b b$ & $* * !$ & & & & * \\
\hline
\end{tabular}




\section{The syllabification of the causative}

Obviously, causative verbs are derived for their morphology and syllable structure in a parallel fashion. This means that the constraints that are responsible for producing the prosodic structure of causatives interact within the same hierarchy with the constraints of morphology, which have been the focus of this paper. In this section, we briefly show how the causative pattern is syllabified. Every causative verb in MA is disyllabic, consisting of two light syllables (i.e. $\sigma \mu \sigma \mu$ ). Typically, this structure is obtained through schwa epenthesis. Schwa in MA is believed to be a purely phonetic and nonmoraic vowel used to break up impermissible consonant clusters (Benhallam, 1980, 1989/1990, 1991; Boudlal, 2001; Bensoukas \& Boudlal, 2012a,b).

$(28)^{\oplus}$<smiles>CCCCCC(C)C</smiles>

Therefore, the syllable structure of the causative is derived through the interaction of independently motivated constraints of syllable well-formedness. These constraints are listed in (29) below:

(29) Constraints deriving syllable structure of causatives:

a. PARSE-segment: Every segment must belong to a syllable.

b. ONSET: Syllables must have an onset.

c. NO-CODA: Syllables must not have a coda.

d. *COMPLEX: Codas and Onsets must not branch.

e. * $\mu / \partial$ : Open schwa syllables are prohibited.

f. DEP-ə: schwa epenthesis is not allowed.

In order to yield the right forms, these constraints interact in the following way:

Table 12. PARSE-Seg, ONSET, * $\mu / \partial$ *COMPLEX $>>$ NOCODA, DEP- $ə$

\begin{tabular}{|c|c|c|c|c|c|c|}
\hline$/ \mathrm{kttb} /$ & PARSE-Seg & ONSET & $* \mu / \partial$ & *COMPLEX & NOCODA & DEP-ə \\
\hline a. kat.tab & & & & & $* *$ & $* *$ \\
\hline b. $k$.t $t b$ & $* * !$ & & & & $*$ & * \\
\hline c. $k \partial . t t a b$ & & & $* !$ & $*$ & $*$ & $* *$ \\
\hline d. $k a t t . a b$ & & $* !$ & & $*$ & $* *$ & $* *$ \\
\hline e. $k a t t . b$ & & & & $* !$ & $*$ & $*$ \\
\hline
\end{tabular}

\footnotetext{
(1) The reason why the first syllable-coda/t/ and the second syllable-coda/b/share one mora with their nucleuses is because schwa in MA in nonmoraic, so, in order to be licensed, schwa gets under the mora of its coda (for more on this, see Boudlal, 2001; Bensoukas \& Boudlal , 2012a, b).
} 
This table shows how the optimal form is selected. Candidate (b) is ruled out for violating the high-ranking constraint Parse-Seg since two of its segments are unsyllabified. Candidate (c) loses in the competition incurring a fatal violation of the constraint against moraic schwas. Candidate (d) violates the high-ranking ONSET constraint since its second syllable lacks an onset. Candidate (e) is excluded for having a complex coda. Therefore, candidate (a) emerges as the winner.

\section{Conclusion}

In this paper, we have argued that the causative formation in MA is achieved via the affixation of a consonantal mora to a root, which translates into a geminate word-medially. More specifically, we have claimed that the designated mora is initially prefixed to the root, and then gets infixed under the pressure of certain phonological requirements, namely the privileged status of the initial root consonant. In OT terms, we have postulated that there is an alignment constraint which stipulates that a mora should be left-aligned to the left edge of the root, hence ALIGN-L ( $\left.\mu_{\mathrm{c}}, \mathrm{Rt}\right)$. Being of abstract prosodic nature, the realization of the causative affix in the output is further ensured by a Realize Morpheme constraint (RM) whose role is to induce some phonological change in output forms, in this case, in accordance with the material provided by the Alignment constraint. These two constraints interact respectively with two different instantiations of feature identity faithfulness constraints. The alignment constraint is believed to be outranked by a faithfulness constraint against the alteration of the weight specification of the initial root consonant, IDENT-RtC $_{1}$ (Weight). This very specific ranking forces the aligned mora not to attach to the initial root consonant and affect the second root consonant instead. The Realize Morpheme constraint, on the other hand, dominates a faithfulness constraint which demands that corresponding input and output segments have matching weight specifications (i.e. IDENT-IO (weight)). This way, output forms emerge phonologically different from their corresponding inputs.

$\begin{array}{llll}\text { Abbreviations and Symbols } & & \\ * & \text { Violation mark } & \text { Caus } & \text { Causative } \\ * ! & \text { Fatal violation } & \text { CL } & \text { Compensatory Lengthening } \\ & \text { Optimal candidate } & \text { DEP } & \text { Dependent } \\ \sqrt{*} & \text { Wrong optimal candidate } & \text { GA } & \text { Generalized Alignment } \\ \sigma & \text { Root } & \text { GCat } & \text { Grammatical Category } \\ \mu_{\mathrm{c}} & \text { Syllable } & \text { IDENT } & \text { Identity } \\ \text { Aff } & \text { Consonantal mora } & \text { IO } & \text { Input-Output } \\ \text { ALIGN-L } & \text { Affix } & \text { MA } & \text { Moroccan Arabic } \\ \text { C } & \text { Left Alignment } & \text { MC } & \text { Morphological Causative } \\ \text { Cat } & \text { Consonant } & \text { OT } & \text { Optimality Theory } \\ & \text { Category } & \text { PCat } & \text { Prosodic Category }\end{array}$


Ayoub Noamane

$\begin{array}{llll}\text { RED } & \text { Reduplication } & \text { Rt } & \text { Root } \\ \text { RM } & \text { Realize Morpheme } & \text { RtC }_{1} & \text { First radical segment } \\ \text { RMT } & \text { Realizational Morphology Theory } & \text { V } & \text { Any vowel }\end{array}$

\section{References}

Anderson, S. R. 1992. A-Morphous Morphology [M]. Cambridge: Cambridge University Press.

Beckman, J. N. 1997. Positional Faithfulness, Positional Neutralisation and Shona Vowel Harmony [J]. Phonology, 14(1):1-46.

Beckman, J. 1998. Positional Faithfulness [D]. Ph.D. Dissertation. Amherst: University of Massachusetts.

Benhallam, A. 1980. Syllable Structure and Rule Types in Arabic [D]. Ph.D. Dissertation. Gainesville: University of Florida.

Benhallam, A. 1989/1990. Moroccan Arabic Syllable Structure [J]. Langues et Littératures, 8:177-191.

Benhallam, A. 1991. On Geminates in Moroccan Arabic [J]. Linguistica Communicatio, 28-40.

Bennis, S. 1992. La formation du Causatif en Arabe Marocain [D]. Mémoire de D.E.S.. Rabat: Faculté des Lettres.

Bennis, S. \& E. Iazzi. 1995. Morphologie du Verbe Causatif en Arabe Marocain [J]. Langues et Littératures, 13:79-96.

Bensoukas, K. 2001. Stem Forms in the Nontemplatic Morphology of Berber [D]. Ph.D. Dissertation. Rabat: Mohammed V University.

Bensoukas, K. \& A. Boudlal. 2012a. The Prosody of Moroccan Amazigh and Moroccan Arabic: Similarities in the phonology of schwa [A]. In T. Borowsky (et al.). (eds.). Prosody Matters: Essays in honor of Lisa Selkirk [C]. London: Equinox, 3-42.

Bensoukas, K. \& A. Boudlal. 2012b. An Amazigh Substratum in Moroccan Arabic: The prosody of Schwa [J]. Langues et Littératures, 22:179-221.

Boudlal, A. 2001. Constraint Interaction in the Phonology and Morphology of Casablanca Moroccan Arabic [D]. Ph.D Dissertation. Rabat: Mohammed V University.

Hayes, B. 1989. Compensatory Lengthening in Moraic Phonology [J]. Linguistic Inquiry, 20(2):253-306.

Hyman, L. 1985. A Theory of Phonological Weight [M]. Dordrecht: Foris.

Inkelas, S. 2006. Reduplication [A]. In K. Brown (ed.). Encyclopedia of Language and Linguistics [C]. Amsterdam: Elsevier, 417-419.

Kurisu, K. 2001. The Phonology of Morpheme Realization [D]. Ph.D. Dissertation. Santa Cruz: University of California.

Lombardi, L. \& J. McCarthy. 1991. Prosodic Circumscription in Choctaw Morphology [J]. Phonology, $8(1): 37-72$.

Loutfi, A. 2017. Morphological Causatives in Moroccan Arabic [A]. Studies in the Linguistic Sciences: Illinois working papers [C]. University of Illinois, Urbana-Champaign.

Marantz, A. 1982. Re reduplication [J]. Linguistic inquiry, 13(3):435-482.

McCarthy, J. 2008. Doing Optimality Theory: Applying theory to data [M]. Oxford: Blackwell.

McCarthy, J. \& A. Prince. 1986. Prosodic Morphology [Z]. Ms. Amherst: University of Massachusetts.

McCarthy, J. \& A. Prince. 1990a. Foot and Word in Prosodic Morphology: The Arabic broken plurals [J]. Natural Language and Linguistic Theory, 8(2):209-83.

McCarthy, J. \& A. Prince. 1990b. Prosodic Morphology and Templatic Morphology [A]. In M. Eid \& J. McCarthy (eds.). Perspectives on Arabic Linguistics: Papers from the second symposium [C]. Amsterdam: John Benjamins, 1-54.

McCarthy, J. \& A. Prince. 1993a. Prosodic Morphology I: Constraint interaction and satisfaction [Z]. Ms. Amherst: University of Massachusetts.

McCarthy, J. \& A. Prince. 1993b. Generalized Alignment [A]. In G. Booij \& J. van Marle. (eds.). Yearbook of Morphology [C]. Dordrecht: Kluwer, 79-153.

McCarthy, J. \& A. Prince. 1995. Faithfulness and Reduplicative Identity [A]. In University of Massachusetts Occasional Papers in Linguistics 18: Papers in Optimality Theory [C]. Rutgers Optimality Archive 60. Camden: Rutgers University, 249-384. 
The Morphophonology of Moroccan Arabic Derived Causatives

McCarthy, J. \& A. Prince. 1999. Faithfulness and Identity in Prosodic Morphology [A]. In R. Kager, H. van der Hulst \& W. Zonneveld (eds.). The Prosody-Morphology Interface [C]. Cambridge: Cambridge University Press, 218-309.

Morén, B. 1999. Distinctiveness, Coercion, and Sonority: A unified theory of weight [D]. Ph.D. Dissertation. College Park: University of Maryland.

Morén, B. 2003. Weight Typology: An optimality theoretic approach [J]. The Linguistic Review, 20(2-4):281-304.

Noamane, A. 2013/2014. Aspects of the Morpho-phonology of Causative Verbs in Moroccan Arabic: An optimality-theoretic approach [M]. Saarbrücken: Lambert Academic Publishing.

Noamane, A. 2018a. Morphological Causatives in Moroccan Arabic: Root-based or word-based? [J]. Asinag, $13: 217-240$

Noamane, A. 2018b. Patterns of Gemination in Moroccan Arabic: Issues in phonology and morphology [D]. Ph.D. Dissertation. Rabat: Mohammed V University.

Noamane, A. 2018c. A Root-and-Prosody Approach to Templatic Morphology and Morphological Gemination in Moroccan Arabic [J]. International Journal of Arabic Linguistics, 4(2):331-369.

Noamane, A. 2019. The Moraic Nature of Geminate Consonants in Moroccan Arabic: Evidence from word-minimality, syllable structure and word formation [J]. International Journal of Arabic Linguistics, 5(2):100-129.

Noamane, A. 2020. Consonant Gemination in Moroccan Arabic: A constraint-based analysis [J]. Journal of Applied Language and Culture Studies, 3:37-68.

Nooteboom, S. G. 1981. Lexical Retrieval from Fragments of Spoken Words: Beginnings vs. endings [J]. Journal of Phonetics, 9(4):407-424.

Prince, A. \& P. Smolensky. 2004. Optimality Theory: Constraint interaction in generative grammar [M]. Malden, MA: Blackwell.

Samek-Lodovici, V. 1992. A Unified Analysis of Crosslinguistic Morphological Gemination [M]. New Brunswick, NJ: Rutgers University.

Ussishkin, A. 2007. Morpheme Position [A]. In P. de Lacy (ed.). The Cambridge Handbook of Phonology [C]. New York: Cambridge University Press, 458-472.

Zellou, G. 2010. Moroccan Arabic Consonant Harmony: A multiple causation hypothesis [A]. Toronto Working Papers in Linguistics [C]. Toronto: University of Toronto, 33:1-15. 